Research Paper

\title{
The Evaluation of Liver Function and Surgical Influence by ICGR 15 after Chemotherapy for Colorectal Liver Metastases
}

\author{
Kiyokazu Hiwatashi ${ }^{1}$, Shinichi Ueno ${ }^{\circledR}{ }^{\bowtie}$, Masahiko Sakoda $^{1}$, Satoshi Iino ${ }^{1}$, Koji Minami $^{1}$, Shinichiro Mori ${ }^{1}$, \\ Yoshiaki Kita ${ }^{1}$, Kenji Baba ${ }^{1}$, Hiroshi Kurahara ${ }^{1}$, Yuko Mataki', Kosei Maemura ${ }^{1}$, Hiroyuki Shinchi ${ }^{3}$, Shoji \\ Natsugoe ${ }^{1}$ \\ 1. Department of Digestive Surgery, Breast and Thyroid Surgery Graduate School of Medical and Dental Sciences Kagoshima University, Sakuragaoka 8-35-1 \\ Kagoshima, 890-8520, Japan. \\ 2. Department of Clinical Oncology, Graduate School of Medical and Dental Sciences Kagoshima University. \\ 3. Faculty of Medical School of Health Sciences, Graduate School of Health Sciences Kagoshima University. \\ $\triangle$ Corresponding author: Shinichi Ueno, MD, PhD, Department of Clinical Oncology, Graduate School of Medical and Dental Sciences Kagoshima University, \\ Sakuragaoka 8-35-1 Kagoshima, 890-8520, Japan. E-mail address: ueno1@m.kufm.kagoshima-u.ac.jp; Tel: +81-99-275-5361; Fax: +81-99-265-7426.
}

() Ivyspring International Publisher. Reproduction is permitted for personal, noncommercial use, provided that the article is in whole, unmodified, and properly cited. See http://ivyspring.com/terms for terms and conditions.

Received: 2015.09.04; Accepted: 2016.01.22; Published: 2016.03.18

\begin{abstract}
Background; Approximately $60 \%$ of patients with colorectal cancer develop liver metastasis at some point after diagnosis. The aim of this study is to investigate whether the evaluation of ICGR 15 preoperatively is a useful clinical indicator of hepatic injury following chemotherapy and to investigate the influence of multiple chemotherapies on liver function.

Results; Mean ICGR 15 values were higher in patients $\geq 65$ years $(P=0.047)$ and in patients with $\geq 3$ cycles $(P=0.022)$ and $\geq 6$ cycles $(P=0.001)$ of systemic chemotherapy. ICGR 15 values tended to be higher in patients with postoperative complications $(P=0.085)$. Patients receiving systemic chemotherapy for $\geq 6$ cycles had higher levels of AST $(P=0.003)$, ALT $(P=0.015)$, and alkaline phosphatase (ALP) $(P=0.041)$. Patients receiving systemic chemotherapy for $\geq 3$ cycles had higher levels of AST $(P=0.015)$ and ALP $(P=0.015)$.

Conclusions; Because the pathological diagnosis is usually established only after operation, preoperative evaluation such as the identification of sinusoidal injury is difficult. Based on this study, higher ICGR 15 values may provide an indication of surgical complications and be a predictor of liver dysfunction following frequent cycles of chemotherapy. Hepatectomy should be performed with the utmost care in such patients, and the number of cycles of preoperative chemotherapy should probably be as low as possible.
\end{abstract}

Key words: ICG, CRLM, chemotherapy.

\section{Introduction}

Colon cancer is the third most common cancer worldwide [1-3]. Approximately $14 \%-25 \%$ of patients with colorectal cancer have liver metastasis at presentation, and up to $60 \%$ of patients develop metastasis at some point after diagnosis [4-7]. Surgical resection is widely accepted as the only potentially curative treatment for colorectal liver metastasis (CRLM), and it is also the only treatment offering long-term survival [8]. Curative resection of liver metastases achieves a 5 -year survival rate of $25 \%-40 \%$ [9-15]. This progress can be attributed to the improvements in surgical techniques, perioperative care, and the emergence of more effective chemotherapy regimens. Neoadjuvant chemotherapy (NAC) is increasingly being used, especially among patients with advanced CRLM. NAC has allowed many previously unresectable tumors to be treated and converted/downsized to make surgery possible. 
Moreover, NAC for patients with resectable disease is also frequently being used [16, 17]. Adam et al. reported a $30 \%$ increase in the 5-year survival rate among patients who underwent hepatectomy after an objective tumor response vs. patients who showed tumor progression while receiving NAC [18]. Thus, the application of NAC for CRLM is likely to increase.

Indocyanine green (ICG) is a water-soluble, anionic compound that mainly binds to plasma proteins after intravenous administration. It is selectively taken up by the hepatocytes and excreted unchanged into the bile [19]. The ICG retention rate at 15 min (ICGR15) has been reported to be effective for preoperative evaluation of hepatic functional reserve [19-23]. Makuuchi's criteria for estimating the extent of hepatectomy have often been applied in Japan; they are based on the values of ICGR15, serum levels of total bilirubin, and existence of ascites, and are suitable indicators for hepatectomy in liver tumors $[20,23]$.

The aims of this study are to investigate whether the evaluation of ICGR15 preoperatively is a useful clinical indicator of hepatic injury following chemotherapy and to investigate the influence of multiple chemotherapies on liver function.

\section{Materials and Methods}

\section{Patients and study groups}

From January 2001 to April 2015, 102 consecutive patients underwent hepatic resection for CRLM in our department. Of them, 92 patients who had undergone hepatectomy for the first time were enrolled and the remaining 10 patients with multiple hepatectomies were excluded. Patients characteristics are showed in Table 1. ICG examination was performed in all patients. CRLM was diagnosed using abdominal ultrasonography, dynamic computed tomography (CT) scans, and magnetic resonance imaging (MRI).

\section{Clinicopathological factors}

Clinicopathological factors selected for evaluation included age, gender, body mass index, alcohol consumption, diabetes mellitus, and preoperative laboratory values [ICGR15 value, prothrombin time, serum aspartate aminotransferase (AST), serum alanine aminotransferase (ALT), serum total bilirubin, serum albumin, and C-reactive protein]. A diagnosis of diabetes mellitus was based on the results of a 75-g oral glucose tolerance test or a random blood glucose measurement of $>200 \mathrm{mg} / \mathrm{dL}$. Excessive alcohol consumption was defined as an average daily consumption of an amount equivalent to $80 \mathrm{~g}$ of pure ethanol for more than10 years. Diabetes mellitus patients enrolled in the study included patients whose symptoms were medically well controlled.

\section{Preoperative management}

Patients were treated with a number of chemotherapy regimens (Table 2). Briefly, the regimens were divided into five types as follows, with the regimens overlapping for each patient: no treatment (31 cases), oral agents (24 cases), FOLFOX-based (34 cases), FOLFILI-based (11 cases), and other chemotherapies (10 cases). In this study, oral chemotherapeutic agents were not included in systemic chemotherapy.

Table 1. Patients characteristics.

\begin{tabular}{ll}
\hline Baseline Characteristics & \\
\hline $\mathrm{N}$ & 92 \\
Age (years) & $64.6 \pm 10.8$ \\
Gender, male : female & $59: 33$ \\
Body mass index $\left(\mathrm{kg} / \mathrm{m}^{2}\right)$ & $22.87 \pm 3.53$ \\
Mean ICGR15 $(\%)$ & $9.34 \pm 5.36$ \\
Maximum size of tumor diameter $(\mathrm{cm})$ & $3.56 \pm 2.22$ \\
No. of tumors & $2.52 \pm 2.31$ \\
Major hepatectomy : Minor hepatectomy & $35: 57$ \\
Clavien-Dindo classification; grade II : gradeIII : grade IV & $14: 2: 0$ \\
and V & \\
\hline
\end{tabular}

Table 2. Chemotherapeutic regimens.

\begin{tabular}{ll}
\hline Chemotherapeuic regimen (overlapping in these cases) & \\
\hline None & 31 \\
Oral & 24 \\
FOLFOX & 5 \\
+bevacizumab & 21 \\
+panitumumab & 4 \\
+cetuximab & 4 \\
FOLFIRI & 7 \\
+bevacizumab & 3 \\
+cetuximab & 1 \\
others & 10
\end{tabular}

Data are presented as number and median \pm standard deviation.

\section{Measuring ICGR 15 levels}

ICG (Dianogreen; Daiichi Sankyo Co. Ltd., Tokyo, Japan; $0.5 \mathrm{mg} / \mathrm{kg}$ body weight) was intravenously injected; $3 \mathrm{ml}$ of venous blood was collected, and the initial concentration was measured for reference. After $15 \mathrm{~min}, 3 \mathrm{ml}$ of venous blood was collected again. ICGR15 was calculated as a percentage using the ratio between the ICG concentration at $15 \mathrm{~min}$ after injection and the initial ICG concentration.

\section{Hepatic resection}

Almost all enrolled patients received colorectal resection and adjuvant or neoadjuvant chemotherapy in another hospital, after which they consulted our department regarding hepatectomy for CRLM. Therefore, the indication for chemotherapy was not standardized for all patients. Some specialists in our department discussed and decided on resectability. 
The type of hepatic resection was based on the results of preoperative diagnostic imaging, intraoperative ultrasonography, and careful attention to liver function. Major hepatectomy was defined as excision of two or more liver segments.

Hepatic resection was performed under intraoperative ultrasound guidance with or without inflow occlusion (Pringle's maneuver). Parenchymal transection was performed using an ultrasonic dissector with bipolar electric cautery. All portal veins in the Glisson's capsule $>1 \mathrm{~mm}$ in diameter were ligated whenever possible using 2-0 or 3-0 braided silk sutures or a vessel clip. The exposed structures were dissected using a tissue sealer. Tests to detect intraoperative bile leakage were routinely performed, and when bile leakage sites were detected on the cut liver surface, these were repaired using $4-0$ or 5-0 monofilament synthetic absorbable sutures.

Table 3. The comparison of Mean ICG value in each category.

\begin{tabular}{|c|c|c|c|}
\hline & \multicolumn{2}{|c|}{ Mean ICGR15 (N=92) } & \multirow{2}{*}{$\frac{\mathrm{P}}{0.047}$} \\
\hline $\begin{array}{l}\text { Age } \geq 65 \\
\text { Yes (49) / No (43) }\end{array}$ & $10.40 \pm 5.74 \%$ & $8.22 \pm 4.66 \%$ & \\
\hline $\begin{array}{l}\text { gender } \\
\text { Men (59) / } \\
\text { women (33) }\end{array}$ & $9.93 \pm 5.59 \%$ & $8.30 \pm 4.75 \%$ & 0.169 \\
\hline $\begin{array}{l}\text { Body mass index } \geq \\
25 \mathrm{~kg} / \mathrm{m} 2 \\
\text { Yes }(20) / \text { No }(72)\end{array}$ & $10.81 \pm 4.54 \%$ & $8.92 \pm 5.53 \%$ & 0.167 \\
\hline $\begin{array}{l}\text { Diabetes Mellitus } \\
\text { Yes (13) / No (79) }\end{array}$ & $9.15 \pm 6.64 \%$ & $9.37 \pm 5.18 \%$ & 0.892 \\
\hline $\begin{array}{l}\text { Alcohol consumption } \\
\text { Yes (11) / No (81) }\end{array}$ & $8.02 \pm 3.87 \%$ & $\quad 9.51 \pm 5.53 \%$ & 0.389 \\
\hline $\begin{array}{l}\text { Chemotherapy } \\
\text { Yes (61) / No (31) }\end{array}$ & $9.77 \pm 5.57 \%$ & $8.68 \pm 4.95 \%$ & 0.317 \\
\hline $\begin{array}{l}\text { Chemotherapy } \\
\geq 3 \text { cycles } \\
\text { Yes (37) / No ( } 55)\end{array}$ & $10.89 \pm 6.25$ & $8.29 \pm 4.44$ & 0.022 \\
\hline $\begin{array}{l}\text { Chemotherapy } \\
\geq 6 \text { cycles } \\
\text { Yes (29) / No (63) }\end{array}$ & $12.1 \pm 6.46 \%$ & $8.11 \pm 4.24 \%$ & 0.001 \\
\hline $\begin{array}{l}\mathrm{T}-\mathrm{Bil} \geq 1.2 \mathrm{mg} / \mathrm{dl} \\
\text { Yes }(6) / \mathrm{No}(86)\end{array}$ & $8.90 \pm 3.84 \%$ & $9.37 \pm 5.47 \%$ & 0.839 \\
\hline $\begin{array}{l}\text { AST } \geq 32 \text { IU/1 } \\
\text { Yes }(14) / \text { No }(78)\end{array}$ & $11.57 \pm 6.19 \%$ & $8.93 \pm 5.15 \%$ & 0.090 \\
\hline $\begin{array}{l}\text { ALT } \geq 37 \text { IU/1 } \\
\text { Yes }(7) / \text { No }(85)\end{array}$ & $9.69 \pm 3.63 \%$ & $9.31 \pm 5.50 \%$ & 0.858 \\
\hline $\begin{array}{l}\text { ALP } \geq 359 \text { IU/1 } \\
\text { Yes }(23) / \text { NO ( } 69)\end{array}$ & $9.67 \pm 6.22 \%$ & $9.22 \pm 5.09 \%$ & 0.735 \\
\hline $\begin{array}{l}\text { Albmin } \geq 4.0 \mathrm{~g} / \mathrm{dl} \\
\text { Yes }(65) / \text { No }(27)\end{array}$ & $8.55 \pm 4.68 \%$ & $/ 11.22 \pm 6.44 \%$ & 0.029 \\
\hline $\begin{array}{l}\text { Prothrombin time } \geq 80 \% \\
\text { Yes (86) / No (5) }\end{array}$ & $9.04 \pm 5.19 \%$ & $\quad 14.64 \pm 6.64 \%$ & 0.023 \\
\hline $\begin{array}{l}\text { CRP } \geq 0.26 \mathrm{~g} / \mathrm{dl} \\
\text { Yes }(30) / \text { No }(62)\end{array}$ & $9.51 \pm 5.38 \%$ & / $9.25 \pm 5.40 \%$ & 0.829 \\
\hline $\begin{array}{l}\text { Hepatectomy } \\
\text { Major (35) / Minor (57) }\end{array}$ & $9.43 \pm 4.88 \%$ & $9.27 \pm 5.68 \%$ & 0.890 \\
\hline $\begin{array}{l}\text { Complication } \\
\text { Yes (16) / No (76) } \\
\text { (Clavian-Dindo classification } \geq 2)\end{array}$ & $11.43 \pm 6.03 \%$ & $8.89 \pm 5.15 \%$ & 0.085 \\
\hline
\end{tabular}

Data are presented as median \pm standard deviation.
Surgical complications were evaluated by the Clavien-Dindo classification [24], and a score higher than grade II was defined as a postoperative complication.

\section{Statistical analyses}

The chi-square test was used to evaluate categorical variables, and the unpaired t-test was used to evaluate continuous variables. Data are presented as mean \pm standard deviation. A probability $(P)$ value of $<0.05$ was considered statistically significant. Statistical analyses were performed using the SPSS statistical software package (version 21; SPSS Inc., Chicago, IL, USA).

\section{Results}

\section{Comparison of mean ICG 15 values in each category}

Mean ICGR15 values in each category are shown in Table 3 . Values were higher in patients $\geq 65$ years $(P=0.047)$ and in patients with $\geq 3$ cycles $(P=0.022)$ and $\geq 6$ cycles $(P=0.001)$ of systemic chemotherapy. Patients with a higher prothrombin time $(P=0.023)$ and higher albumin levels $(P=0.029)$ showed higher ICGR15 values. ICGR15 values tended to be higher in patients with postoperative complications $(P=0.085)$. In detail, postoperative complications were postoperative bleeding, ileus, cholangitis, the abnormalities of liver function, the leakage of choledochojejunostomy, unknown fever, pleural or abdominal effusion, arrhythmia. There was no postoperative mortality.

\section{Clinical characteristics of patients receiving systemic chemotherapy for $\geq 6$ cycles vs. $<6$ cycles and for $\geq 3$ cycles vs. $<3$ cycles}

Firstly, we examined the clinical characteristics of patients receiving systemic chemotherapy for $\geq 6$ cycles $v$ s. $<6$ cycles based on past studies on sinusoidal injury following multiple chemotherapies (Table 4). Compared with patients receiving systemic chemotherapy for $<6$ cycles, those receiving systemic chemotherapy for $\geq 6$ cycles had higher levels of AST $(P=0.003)$, ALT $(P=0.015)$, and alkaline phosphatase (ALP) $(P=0.041)$; lower levels of albumin $(P=0.041)$; and higher values of ICGR15 $(P=0.001)$. These results were indicative of decreased liver function in the group receiving systemic chemotherapy for $\geq 6$ cycles, probably because of the higher number of chemotherapy cycles. However, there were no significant differences between the two groups in the occurrence of complications. 
Table 4. Clinical characteristics of patients receiving systemic chemotherapy.

\begin{tabular}{|c|c|c|c|c|c|c|}
\hline Chemotherapy & $\geq 6$ cycles $(29)$ & $<6$ cycles $(63)$ & $\mathrm{P}$ & $\geq 3$ cycles $(37)$ & $<3$ cycles $(55)$ & $\mathrm{P}$ \\
\hline Age (years) & $63.7 \pm 11.1$ & $65.1 \pm 10.8$ & 0.560 & $63.0 \pm 10.8$ & $65.8 \pm 10.8$ & 0.230 \\
\hline Gender (male : female) & $17: 12$ & $42: 21$ & 0.559 & $21: 16$ & $38: 17$ & 0.226 \\
\hline Body mass index $\left(\mathrm{kg} / \mathrm{m}^{2}\right)$ & $23.81 \pm 4.01$ & $22.44 \pm 3.23$ & 0.083 & $23.32 \pm 3.94$ & $22.57 \pm 3.23$ & 0.315 \\
\hline ICG, $(\%)$ & $12.10 \pm 6.46$ & $8.11 \pm 4.24$ & 0.001 & $10.89 \pm 6.25$ & $8.29 \pm 4.44$ & 0.022 \\
\hline T-Bil, (mg/dL) & $0.710 \pm 0.214$ & $0.729 \pm 0.250$ & 0.736 & $0.716 \pm 0.222$ & $0.727 \pm 0.251$ & 0.829 \\
\hline AST, (U/L) & $33.41 \pm 23.11$ & $23.29 \pm 8.30$ & 0.003 & $31.19 \pm 21.09$ & $23.31 \pm 8.48$ & 0.015 \\
\hline $\mathrm{ALT},(\mathrm{U} / \mathrm{L})$ & $26.07 \pm 19.61$ & $18.89 \pm 8.18$ & 0.015 & $24.14 \pm 17.83$ & $19.15 \pm 8.55$ & 0.076 \\
\hline $\mathrm{ALP},(\mathrm{U} / \mathrm{L})$ & $342.17 \pm 180.52$ & $278.93 \pm 109.89$ & 0.041 & $341.14 \pm 174.80$ & $270.43 \pm 99.07$ & 0.015 \\
\hline Prothrombin time, $(\%)$ & $106.31 \pm 12.19$ & $96.16 \pm 11.26$ & $<0.001$ & $104.19 \pm 11.97$ & $96.11 \pm 11.75$ & 0.002 \\
\hline Albumin, (g/dL) & $3.92 \pm 0.46$ & $4.11 \pm 0.40$ & 0.041 & $4.016 \pm 0.43$ & $4.08 \pm 0.42$ & 0.457 \\
\hline $\mathrm{CRP},(\mathrm{mg} / \mathrm{dL})$ & $0.397 \pm 0.659$ & $0.931 \pm 1.95$ & 0.543 & $0.440 \pm 0.728$ & $0.628 \pm 2.06$ & 0.595 \\
\hline Maximum size of tumor diameter $(\mathrm{cm})$ & $3.35 \pm 1.95$ & $3.71 \pm 2.34$ & 0.471 & $3.84 \pm 2.47$ & $3.43 \pm 2.04$ & 0.383 \\
\hline No. of tumors & $2.72 \pm 2.46$ & $2.43 \pm 2.25$ & 0.571 & $2.84 \pm 2.30$ & $2.31 \pm 2.31$ & 0.529 \\
\hline Major hepatectomy, (case) (\%) & $11,37.9$ & $24,38.1$ & 0.988 & $16,43.2$ & $19,34.5$ & 0.399 \\
\hline Operation time, (min) & $412.5 \pm 153.5$ & $359.5 \pm 126.1$ & 0.095 & $399.5 \pm 141.5$ & $359.8 \pm 131.5$ & 0.182 \\
\hline Bleeding, (ml) & $1400.6 \pm 1410.23$ & $1590.8 \pm 1169.3$ & 0.408 & $1353.2 \pm 1375.9$ & $1154.0 \pm 1156.7$ & 0.465 \\
\hline $\begin{array}{l}\text { Complication, }(\text { case })(\%) \\
\text { (Clavian- Dindo classification } \geq 2 \text { ) }\end{array}$ & $4,13.8$ & $12,19.0$ & 0.382 & $5,13.5$ & $11,20.0$ & 0.421 \\
\hline
\end{tabular}

We also investigated the clinical characteristics of patients receiving systemic chemotherapy for $\geq 3$ cycles vs. $<3$ cycles to elucidate the number of chemotherapy cycle inducing liver injury (Table 4). Patients receiving systemic chemotherapy for $\geq 3$ cycles had higher levels of AST $(P=0.015)$ and ALP $(P$ $=0.015)$; higher prothrombin time $(P<0.001)$; and higher ICGR15 values $(P=0.022)$. ALT values tended to be higher in patients receiving $\geq 3$ cycles $(P=0.076)$.

\section{Discussion}

The use of preoperative chemotherapy for CRLM is increasing worldwide. However, it remains unclear how many chemotherapy cycles induce liver dysfunction. Although there are some reports on postoperative pathological evaluations following frequent chemotherapies $[19,25,26]$, no preoperative indicators for liver injury have been identified yet.

Nakano et al. reported that sinusoidal injury increased in patients with CRLM receiving $\geq 6$ cycles of oxaliplatin-based preoperative chemotherapy; in addition, ICGR15 values and postoperative total bilirubin levels were significantly elevated in patients presenting with sinusoidal injury [25]. Karoui et al. also reported that preoperative chemotherapy with or without oxaliplatin, irrespective of the number of cycles, was significantly associated with sinusoidal dilatation, atrophy of hepatocytes, hepatocyte necrosis, and incidence of postoperative complications [26]. In the present study, although there was no significant difference in ICGR15 values between the chemotherapy and the non-chemotherapy groups (Table 3 ), the values were higher in the group receiving $\geq 3$ cycles $(10.89 \% \pm$ $6.25 \%)$ and $\geq 6$ cycles $(12.1 \% \pm 6.46 \%)$ of systemic chemotherapy, with significant differences (Tables 3 and 4). With regard to ICGR15 values and frequent chemotherapies, Takamoto et al. reported that the mean initial ICGR15 value in patients receiving $\geq 6$ cycles of chemotherapy was significantly higher than that in those receiving $<6$ cycles in 21 patients. Moreover, they reported that ICGR15 values improved after chemotherapy cessation [9]. According to our data, patients with decreased liver synthetic function, i.e., lower prothrombin time and lower albumin levels, had higher ICGR15 values (prothrombin time, $14.64 \% \pm 6.64 \%$; albumin, $11.22 \%$ $\pm 6.44 \%$ (Table 3). Although not statistically significant $(P=0.085)$, ICGR15 values tended to be higher in patients with complications $(11.43 \% \pm$ $6.03 \%$ ) (Table 3). Moreover, ICGR15 values were higher in patients aged $\geq 65$ years $(10.4 \% \pm 5.74 \%)$, which may reflect the association of organ deterioration with old age. The standard value of ICGR15 is set as $<10 \%$. According to these data, when ICGR15 values were higher in patients $\geq 10 \%$, the patients had liver damage and we should take care of surgical complications.

When we divided patients into groups receiving $\geq 6$ cycles of systemic chemotherapy vs. those receiving $<6$ cycles, ICGR15 values were significantly higher in the former group. Therefore, we compared the clinical characteristics of the patients in the two groups (Table 4). Expectedly, data from several types of laboratory tests revealed a significantly decreased liver function, including ICGR15 values. Although ICGR15 values were higher in patients with complications (Table 3), there was no significant difference in the occurrence of complications in patients receiving $\geq 6$ cycles of chemotherapy vs. those who received $<6$ cycles (Table $4)$. Additionally, there were not a difference between ICG value and the type of complications. Liver 
function, including ICGR15 values, was obviously worse in patients receiving $\geq 6$ cycles of systemic chemotherapy. We performed the same analysis on patients receiving $\geq 3$ cycles vs. $<3$ cycles of chemotherapy. Again, several laboratory tests reflected decreased liver function, with significant differences in the ICGR15 values, in patients receiving $\geq 3$ cycles of chemotherapy, similar to the findings with 6 cycles (Table 4). Several studies have reported that pathological abnormalities arise only following $\geq 6$ cycles of systemic chemotherapy $[9,25]$, but our analysis indicated that laboratory abnormalities suggestive of liver dysfunction appear after $\geq 3$ cycles of systemic chemotherapy. The preoperative chemotherapy, which prolongs overall survival after hepatectomy, does not currently exist for CRLM. Although conversion chemotherapy must be performed for patients with borderline resectable or initially unresectable CRLM, resectable CRLM may be resected without preoperative chemotherapy, and preoperative chemotherapy may be limited to a few cycles based on the results of this study.

With regard to maximum size of tumor diameter and the number of tumors, there were no differences between $\geq 6$ cycles and $<6$ cycles, $\geq 3$ cycles and $<3$ cycles of chemotherapy. (Tables 4). This is because chemotherapy was performed at other hospitals; hence, the criteria for chemotherapy were not standardized initially.

Because the pathological diagnosis is usually established only after operation, preoperative evaluation such as the identification of sinusoidal injury is difficult. Based on this study, higher ICGR15 values, which are technically easy to measure preoperatively, may provide an indication of surgical complications and be a predictor of liver dysfunction following frequent cycles of chemotherapy; hepatectomy should be performed with the utmost care in such patients, and the number of cycles of preoperative chemotherapy should probably be as low as possible.

\section{Acknowledgements}

This work was supported by KAKENHI (No. 40322317 and No. 15K10031) to S.U. and K.H.

\section{Competing Interests}

The authors have declared that no competing interest exists.

\section{References}

1. Spolverato G, Ejaz A, Azad N, et al. Surgery for colorectal liver metastases: The evolution of determining prognosis. World J Gastrointest Oncol. 2013; 5: 207-21.

2. Siegel R, Naishadham D, Jemal A. Cancer statistics, 2013. CA Cancer J Clin. 2013; 63: 11-30.
3. Sawyers CL, Abate-Shen C, Anderson KC, et al. AACR Cancer Progress Report 2013. Clin Cancer Res. 2013; 19: S4-98.

4. Leporrier J, Maurel J, Chiche L, et al. A population-based study of the incidence, management and prognosis of hepatic metastases from colorectal cancer. Br J Surg. 2006; 93: 465-74.

5. Mayo SC, Heckman JE, Shore AD et al. Shifting trends in liver-directed management of patients with colorectal liver metastasis: a population-based analysis. Surgery. 2011; 150: 204-16.

6. Andres A, Toso C, Adam R, et al. A survival analysis of the liver-first reversed management of advanced simultaneous colorectal liver metastases: a LiverMetSurvey-based study. Ann Surg. 2012; 256: 772-8.

7. Cardona K, Mastrodomenico P, D'Amico F, et al. Detailed pathologic characteristics of the primary colorectal tumor independently predict outcome after hepatectomy for metastases. Ann Surg Oncol. 2013; 20: 148-54.

8. Jaeck D, Bachellier P, Guiguet $\mathrm{M}$, et al. Long-term survival following resection of colorectal hepatic metastases. Association Française de Chirurgie. Br J Surg. 1997; 84: 977-80.

9. Takamoto T, Hashimoto T, Sano K, et al. Recovery of liver function after the cessation of preoperative chemotherapy for colorectal liver metastasis. Ann Surg Oncol. 2010; 17: 2747-55.

10. Nordlinger B, Guiguet M, Vaillant JC, et al. Surgical resection of colorectal carcinoma metastases to the liver. A prognostic scoring system to improve case selection, based on 1568 patients. Association Française de Chirurgie. Cancer. 1996; 77: 1254-62.

11. Rees M, Plant G, Bygrave S. Late results justify resection for multiple hepatic metastases from colorectal cancer. Br J Surg. 1997; 84: 1136-40.

12. Fong Y, Fortner J, Sun RL, et al. Clinical score for predicting recurrence after hepatic resection for metastatic colorectal cancer: analysis of 1001 consecutive cases. Ann Surg. 1999; 230: 309-18.

13. Giacchetti S, Itzhaki M, Gruia G, et al. Long-term survival of patients with unresectable colorectal cancer liver metastases following infusional chemotherapy with 5-fluorouracil, leucovorin, oxaliplatin and surgery. Ann Oncol. 1999; 10: 663-9.

14. Choti MA, Sitzmann JV, Tiburi MF, et al. Trends in long-term survival following liver resection for hepatic colorectal metastases. Ann Surg. 2002; 235: 759-66.

15. Adam R, Pascal G, Azoulay D, et al. Liver resection for colorectal metastases: the third hepatectomy. Ann Surg. 2003; 238: 871-83.

16. Tanaka K, Adam R, Shimada $\mathrm{H}$, et al. Role of neoadjuvant chemotherapy in the treatment of multiple colorectal metastases to the liver. Br J Surg. 2003; 90 : 963-9.

17. Bismuth $\mathrm{H}$, Adam $\mathrm{R}$, Lévi $\mathrm{F}$, et al. Resection of nonresectable liver metastases from colorectal cancer after neoadjuvant chemotherapy. Ann Surg. 1996; 224: 509-20.

18. Adam R, Pascal G, Castaing D, et al. Tumor progression while on chemotherapy: a contraindication to liver resection for multiple colorectal metastases? Ann Surg. 2004. 2013; 240: 1052-61.

19. Wakiya T, Kudo D, Toyoki $\mathrm{Y}$, et al. Evaluation of the usefulness of the indocyanine green clearance test for chemotherapy-associated liver injury in patients with colorectal cancer liver metastasis. Ann Surg Oncol. 2014; 21: 167-72.

20. Imamura H, Sano K, Sugawara Y, et al. Assessment of hepatic reserve for indication of hepatic resection: decision tree incorporating indocyanine green test. J Hepatobiliary Pancreat Surg. 2005; 12: 16-22.

21. Kubota K, Makuuchi M, Kusaka K, et al. Measurement of liver volume and hepatic functional reserve as a guide to decision-making in resectional surgery for hepatic tumors. Hepatology. 1997; 26: 1176-81.

22. Seyama Y, Kokudo N. Assessment of liver function for safe hepatic resection. Hepatol Res. 2009; 39: 107-16.

23. Miyagawa S, Makuuchi M, Kawasaki S, et al. Criteria for safe hepatic resection. Am J Surg. 1995; 169: 589-94.

24. Dindo D, Demartines N, Clavien PA. Classification of surgical complications: a new proposal with evaluation in a cohort of 6336 patients and results of a survey. Ann Surg. 2004; 240: 205-13

25. Nakano H, Oussoultzoglou E, Rosso E, et al. Sinusoidal injury increases morbidity after major hepatectomy in patients with colorectal liver metastases receiving preoperative chemotherapy. Ann Surg. 2008; 247: 118-24.

26. Karoui M, Penna C, Amin-Hashem M, et al. Influence of preoperative chemotherapy on the risk of major hepatectomy for colorectal liver metastases. Ann Surg. 2006; 243: 1-7. 